\title{
Preliminary Development and Testing of a Self-Injecting Gallium MPD Thruster
}

\author{
Robert E. Thomas* and Rodney L. Burton ${ }^{\dagger}$ \\ University of Illinois, Urbana, IL, 61801 \\ Kurt A. Polzin \\ NASA-Marshall Space Flight Center, Huntsville, AL, 35812
}

\begin{abstract}
Discharge current and terminal voltage measurements were performed on a gallium electromagnetic thruster at discharge currents in the range of 20-54 kA. It was found that the arc impedance has a value of 6-7 $\mathrm{m} \Omega$ at peak current. The absence of high-frequency oscillations in the terminal voltage trace indicates lack of the "onset" condition often seen in MPD arcs, suggesting that a sufficient number of charge carriers are present for current conduction. The mass ablated per pulse was not measured experimentally; however the mass flow rate was calculated using an ion current assumption and an anode power balance. Measurement of arc impedance predicts a temperature of $3.5 \mathrm{eV}$ which from Saha equilibrium corresponds to $Z=2.0-3.5$, and assuming $Z=2$ yields an Isp of $3000 \mathrm{~s}$ and thrust efficiency of $50 \%$.
\end{abstract}

\section{Nomenclature}

$\begin{array}{ll}b & =\text { geometric constant, }(\mathrm{H} / \mathrm{m}) \\ c & =\text { specific heat }(\mathrm{J} / \mathrm{kg}-\mathrm{K}) \\ e & =\text { elementary charge }(\mathrm{C}) \\ h & =\text { enthalpy }(\mathrm{J} / \mathrm{kg}) \\ I & =\text { discharge current }(\mathrm{A}) \\ k & =\text { Boltzmann constant }(\mathrm{J} / \mathrm{K}) \\ L & =\text { inductance }(\mathrm{H}) \\ m & =\text { ion mass }(\mathrm{kg}) \\ P & =\text { Power }(\mathrm{W}) \\ r_{i} & =\text { inner electrode radius }(\mathrm{m}) \\ r_{o} & =\text { outer electrode radius }(\mathrm{m}) \\ t & =\text { time }(\mathrm{s}) \\ T & =\text { temperature }(\mathrm{K}) \\ u_{e} & =\text { exhaust velocity }(\mathrm{m} / \mathrm{s})\end{array}$

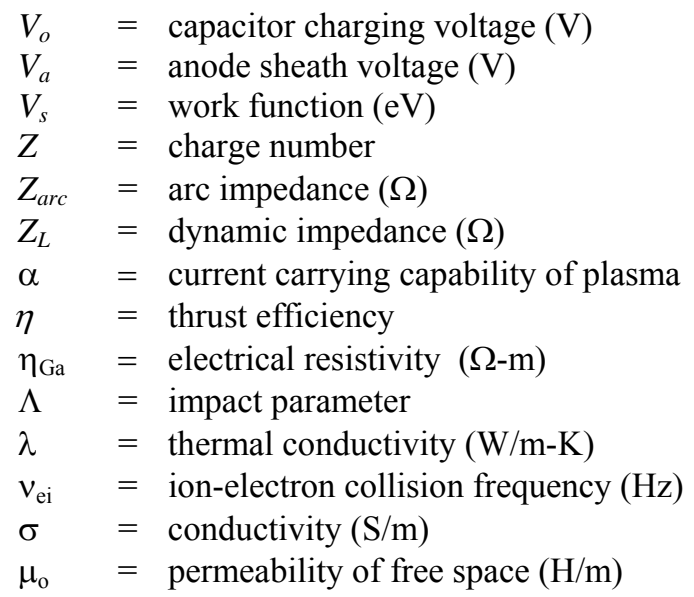

\section{Introduction}

$\mathrm{T}$

HE gallium electromagnetic (GEM) thruster ${ }^{1,2}$ uses a high-current arc discharge to enable operation at high exhaust velocities $(15-30 \mathrm{~km} / \mathrm{s})$. Gallium appears to offer several advantages over propellants currently in use. The non-toxicity and liquid temperature range $\left(30^{\circ} \mathrm{C}-2204^{\circ} \mathrm{C}\right)$ provide numerous systems advantages, while the high atomic mass and low ionization potential $(5.99 \mathrm{eV})$ predict low frozen flow losses. A previous study ${ }^{3}$ has presented performance estimates and emission spectroscopy measurements for a $20 \mathrm{~J} /$ pulse gallium plasma source.

\footnotetext{
${ }^{*}$ Graduate Research Assistant, Department of Aerospace Engineering, Student Member AIAA

${ }^{\dagger}$ Professor, Department of Aerospace Engineering, Associate Fellow AIAA

* Propulsion Research Scientist, Propulsion Research and Technology Applications Branch, Propulsion Systems Dept., Senior Member AIAA.
}

1

American Institute of Aeronautics and Astronautics 
In this paper current and voltage data are presented on a GEM thruster powered by a $1.4 \mathrm{~kJ}$ pulse forming network (PFN). In the present design, a low energy spark plug pre-ionizes propellant from a center gallium anode, and the ablation products expand radially towards the inner walls of the outer cathode. When the gallium bridges the electrodes, it effectively acts as a switch causing the main discharge to commence, with the Lorentz force accelerating the gallium plasma axially to produce thrust.

A key issue in the operation of the GEM thruster is that of mass injection. Previous electromagnetic accelerators have operated in various modes, which can be classified by the injection scheme of the propellant. The detonation (snowplow) acceleration mode is established when the thruster barrel is prefilled with gas, and a moving current sheet accelerates the propellant. Gas-fed deflagration MPDTs employ a stationary $\mathbf{j} \times \mathbf{B}$ force distribution, with the propellant fed from the back, ionized, and then pumped through the current sheet in a relatively efficient acceleration process. In most pulsed plasma thrusters (PPTs), the insulator material is ablated and entrained in an accelerating current sheet to produce thrust. The GEM thruster differs from prior EMTs in that the central electrode is vaporized by the discharge to provide the ionized material, and the arc thus controls the mass flow rate. A summary of various thrusters along with their corresponding injection schemes is given in Table 1. Also tabulated is the arc impedance, which is calculated by dividing the arc voltage $V_{\text {arc }}$ by the discharge current $I$.

Table 1. Comparison of Pulsed Coaxial EM Accelerator Injection Modes

\begin{tabular}{cccccc}
\hline $\begin{array}{c}\text { Accelerator } \\
\text { Type }\end{array}$ & Propellant & $\begin{array}{c}\text { Injection } \\
\text { Mode }\end{array}$ & $\begin{array}{c}\text { Fast } \\
\text { Valve }\end{array}$ & $\begin{array}{c}\text { Injector/ } \\
\text { Switch }\end{array}$ & $\begin{array}{c}\text { Arc } \\
\text { Impedance, } \\
\text { m } \boldsymbol{\Omega}\end{array}$ \\
\hline $\begin{array}{c}\text { Marshall Gun } \\
\text { Deflagration Gun }\end{array}$ & Deuterium & Gas-puff & Yes & No & 6 \\
Solid-Fed MPD & Hydrogen & Gas-fed & Yes & No & 50 \\
Self-Field MPD $^{7}$ & Teflon & Ablation & No & Yes & 9 \\
Gas-Fed PPT $^{8}$ & Argon & Gas-fed & Yes & Yes & 7 \\
Solid-Fed PPT & Argon & Gas-fed & Yes & Yes & 10 \\
Lorentz Force Accelerator & Teflon & Ablation & No & Yes & 14 \\
Self-Injecting MPD & Lithium & Vapor-fed & No & No & 59 \\
\hline & Gallium & Evaporation & No & Yes & 6 \\
\hline
\end{tabular}

Performance estimates for the GEM thruster have been presented in Ref. [3]. Two parameters of particular interest are the ion Larmor radius $R_{L}$ and the charge carrier parameter $\alpha$, which represents the fraction of the discharge current that can be carried by the number of ionized particles present

$$
\alpha \equiv \frac{Z e}{m I} \frac{\mathrm{d} m}{\mathrm{~d} t}
$$

By examining prior MPD performance data, one can conclude that efficient operation of EMTs occurs only when there are enough ion charge carriers present to conduct the current and when the Larmor radius is smaller than the thruster channel. For heavier propellants such as gallium this implies:

- The discharge current must scale with the ion mass and exhaust velocity to keep the Larmor radius small.

- The propellant mass flow rate must scale with ion mass and discharge current to maintain a high number of charge carriers, i.e. $\alpha \geq 1$. That is, thrusters using heavier propellants such as gallium need to be operated at much higher mass flow rates than argon or hydrogen to provide enough currentcarrying particles.

Consequently, the present experiments were conducted at relatively high discharge currents (20-54 kA). It was assumed that the arc would vaporize the proper amount of gallium to sustain the discharge; that is, the mass flow rate was not actively controlled during the experiments. 


\section{Experimental Apparatus}

\section{A. Testing Facilities}

Tests were conducted at the University of Illinois Electric Propulsion Laboratory. The thruster was mounted into a 5way vacuum cross, which is attached to the main vacuum chamber. A baffle was inserted into the 5-way cross to condense ejected gallium particles before they reach the main chamber. Vacuum was maintained by a TPH1500 turbomolecular pump, which is backed by two Roots blowers and two Kinney mechanical displacement pumps. The base pressure of the facility during testing was $5 \times 10^{-5}$ torr.

A ten-section, 5-line pulse forming network (PFN) was used to power the thruster. Each section consists of a $88 \mu \mathrm{f}$ capacitors charged to a maximum of $800 \mathrm{~V}$, in series with a $85 \mathrm{nH}$ inductor, for a total of 50 capacitors yielding a bank energy of $1.4 \mathrm{~kJ}$. A copper sheet with punched holes was laid over the capacitors to provide a common ground (ground plane). Brass standoffs with a height of $3.8 \mathrm{~cm}$ were machined to provide spacing between the stage inductors and the ground plane. The section inductors were composed of 9 cm long, $0.32 \mathrm{~cm}\left(1 / 8^{\prime \prime}\right)$ diameter copper rod, yielding the section inductance of $\sim 85 \mathrm{nH}$. The five PFN lines were connected in parallel using a bus made of $2.5 \mathrm{~cm}$ wide copper strip. To minimize stray inductances in the charging

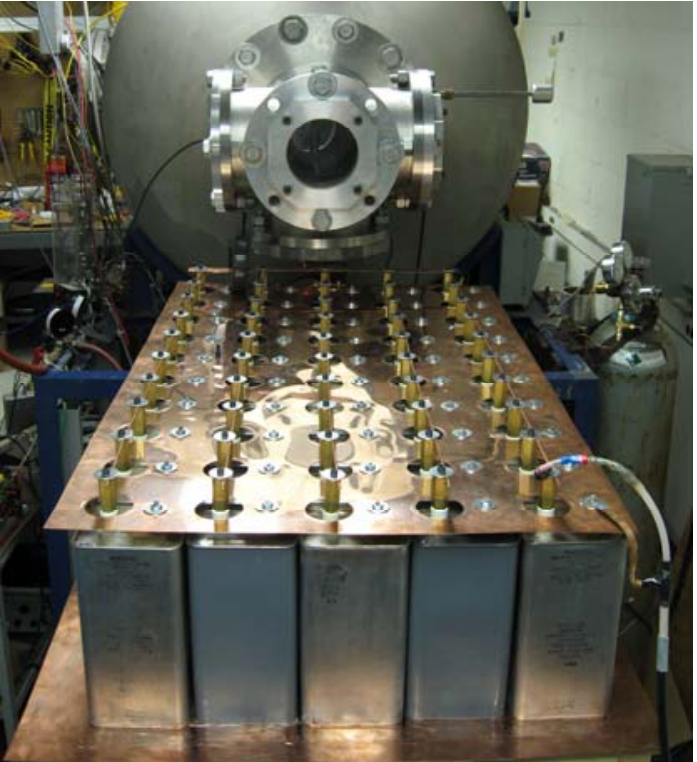

Figure 1. $3.2 \mathrm{~kJ}, 31 \mathrm{~m} \Omega$ pulse forming network. circuit, the PFN was mounted directly near the vacuum chamber, as shown in Fig. 1. A $7.0 \mathrm{~cm}$ wide strip of copper sheet formed the transmission line. The capacitors were charged using a Hipotronics DC power supply.

\section{B. Discharge Initiation}

Arc initiation in a vacuum environment is difficult due to the extremely low vapor pressure of the gallium propellant. Prior experiments ${ }^{3}$ used a thin layer of carbon to bridge the cathode and anode, creating a conductive path for the discharge current. While successful in initiating breakdown, a fraction of the discharge energy was lost in excited and ionized carbon atomic states. In the present experiment, a spark plug was used to initiate the discharge. The igniter plug used is a semiconductor-type aircraft turbine combustor spark plug mounted $5 \mathrm{~cm}$ from the face of the thruster. It is powered by a $20 \mathrm{~J}$ non-reversing current pulse. It was found that after $\sim 50$ shots the spark plug became clogged with gallium and would no longer fire. This was remedied by firing the igniter plug several hundred times in between tests to keep it clean.

\section{Operating Polarity}

Unlike prior MPDTs, the GEM thruster operates with a central anode. This is in part due to the discharge being initiated with a spark plug. Prior PPT studies ${ }^{9}$ experienced difficulties igniting the discharge with a central cathode. This was attributed to electrons being unable to reach the center electrode, as they were lost to the positive outer electrode and/or repelled by the negative center electrode (illustrated in Fig. 2). 

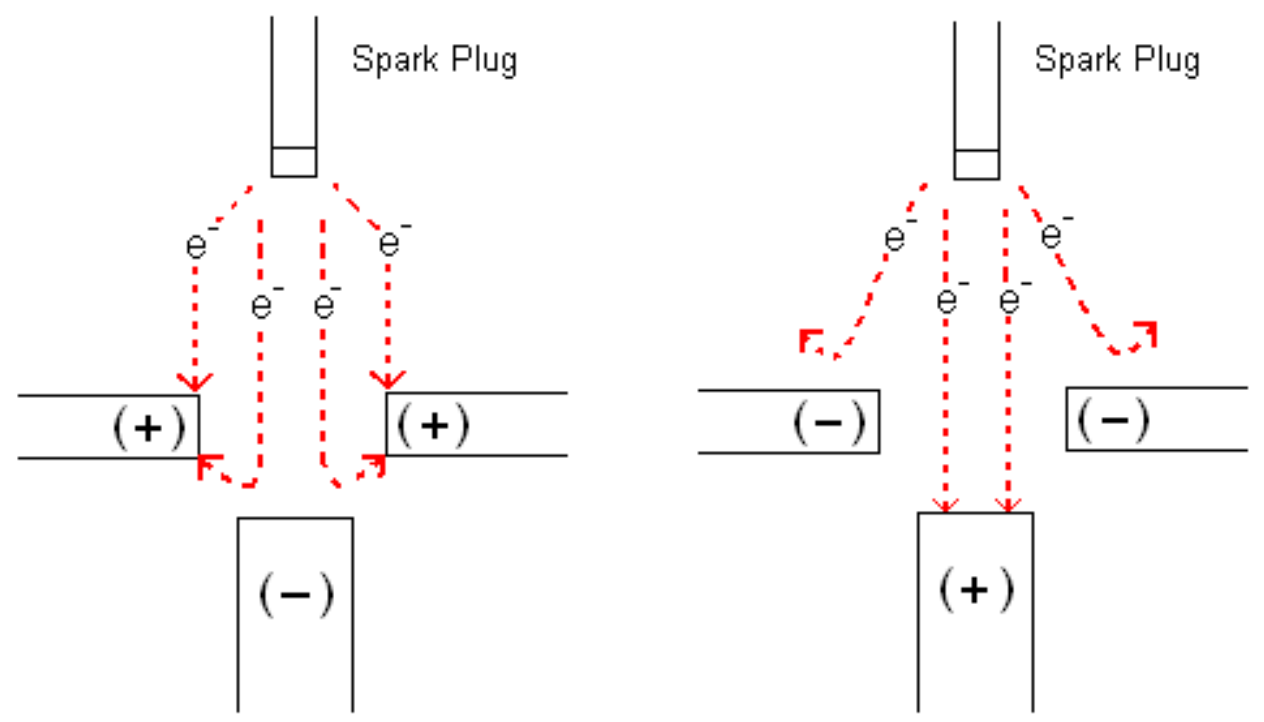

Figure 2. Left: An insufficient number of electrons are able to reach the center electrode when it is negatively biased. Right: Electrons can reach a positively biased center electrode.

Additionally, the influence of operating polarity on ion trajectory motion in a coaxial, deflagration mode MPDT has been discussed in a previous paper. ${ }^{2}$ In that work, two cases were presented: a central cathode (the traditional configuration for MPDTs) and a central anode (such as is found in PPTs). In the case of the central cathode, ions created near the outer electrode enter a region of strong $B$-field as they are accelerated radially inward by the electric field, and they are deflected axially by the $q \mathbf{u x} \mathbf{B}$ force. For a central anode, ions are created along the axis in the region of strong $B$-field. These ions are more easily deflected axially because they possess a smaller radial velocity, and consequently a smaller Larmor radius, than in the case of a central cathode.

\section{Electrode Assembly}

The coaxial gallium pulsed plasma source is shown in Fig. 3. The stainless steel outer electrode has outer and inner diameters of $5.72 \mathrm{~cm}$ and $2.22 \mathrm{~cm}$, respectively. A threaded Teflon tube fitted inside a boron nitride (BN) insulator electrically separates the inner and outer electrode. A $5.0 \mathrm{~mm}$ diameter hole drilled through the center of the Teflon allows the gallium to make electrical contact with a brass standoff, which in turn is connected to the PFN outside of the chamber. Teflon was used to contain the gallium as the boron nitride was too brittle to withstand the high pressures at the face of the thruster during operation.

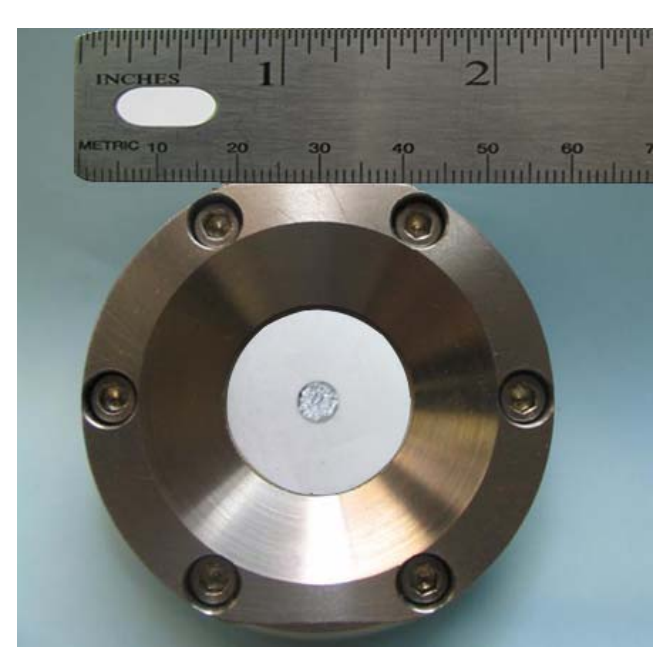

(a)

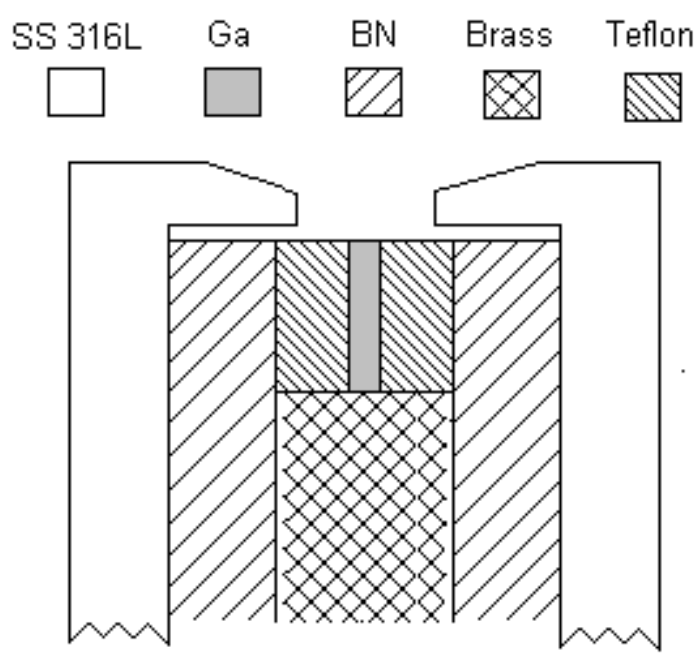

(b)

Figure 3. a) Photograph and b) cross-section of the coaxial electrode assembly. 
The inner diameter of the inner electrode was chosen to satisfy two conditions. It has experimentally been found that when the outer to inner electrode ratio exceeds 5, MPDTs become prone to the spoke instability. ${ }^{11}$ Additionally, for proper operation, it is necessary to heat the gallium surface from room temperature to boiling $(2477 \mathrm{~K})$ in a time comparable to the current pulse rise time. For a wall exposed to a power flux $P$, for a time $\tau$, the temperature increase is given by ${ }^{12}$

$$
\Delta T=\frac{1}{2(\pi \rho c \lambda)^{1 / 2}} \frac{P_{e l}}{\pi r_{i}^{2}} \tau^{1 / 2}
$$

where $\rho, c, \lambda$ are the density, specific heat, and thermal conductivity of gallium. The power flux $P_{e l}$ is the power received by the anode surface due to the incoming flux of electrons, which is composed of 1 ) the power associated with the anode voltage drop $V_{a}, 2$ ) the heating due to electron absorption on the anode surface, and 3) the power that accounts for the transport of electron thermal energy from the plasma ${ }^{13}$

$$
P_{e l}=I\left(V_{S}+\frac{5}{2} \frac{k T_{e}}{e}\right)+\int I V_{a} \mathrm{~d} A
$$

The surface area over which the discharge current acts is currently an unknown. The possible presence of anode spots, the movement of such spots, and the convection of heat between the spots complicate this problem. For the purpose of this calculation, it is assumed that the current uniformly heats the entire anode surface. This assumption yields heating times in the range of 5-10 $\mu$ s for a $50 \mathrm{kA}$ pulse.

\section{E. Current and Voltage Measurements}

Current and voltage measurements across the discharge are important as they provide information on the thruster impedance, which is related to the efficiency of the thrust generating process. Measurements were obtained for capacitor charging voltages in the range of $V_{o}=300-800 \mathrm{~V}$. A Pearson 4418 current monitor and Tektronix P6015A voltage probe were used to measure the discharge current and terminal voltage, respectively. Representative traces are shown in Figs. 5 and 6. Note that the PFN impedance is well-matched to the arc impedance, minimizing current reversal.

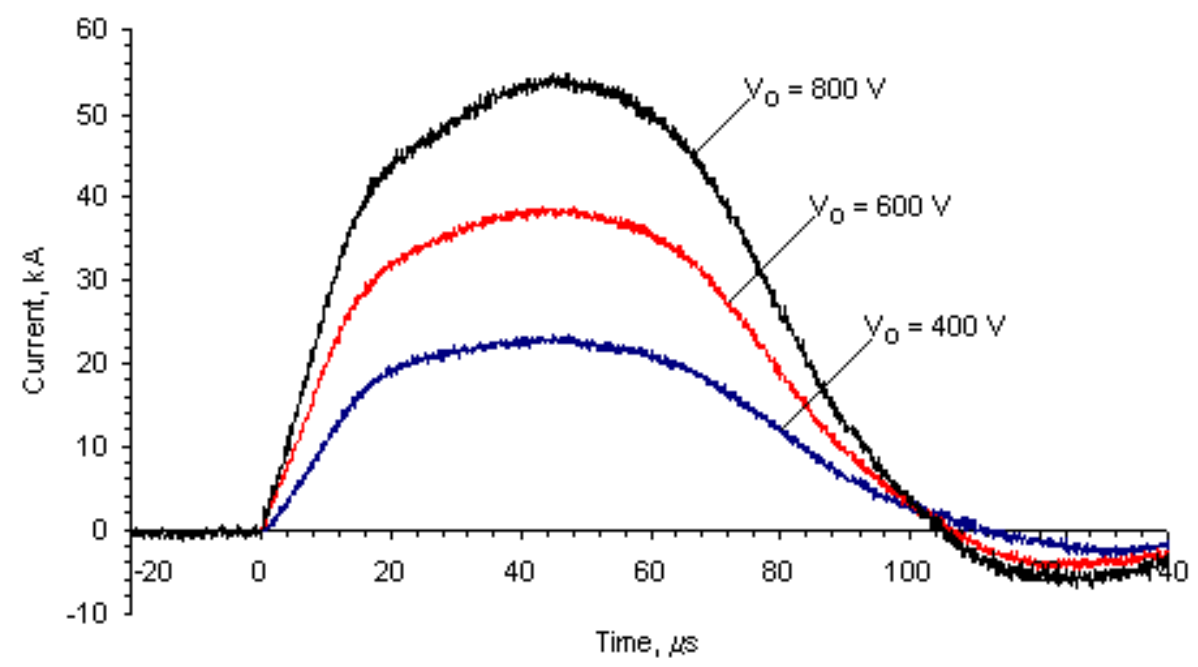

Figure 5. Discharge current waveforms for a PFN charging voltage of 400, 600, and $800 \mathrm{~V}$. 


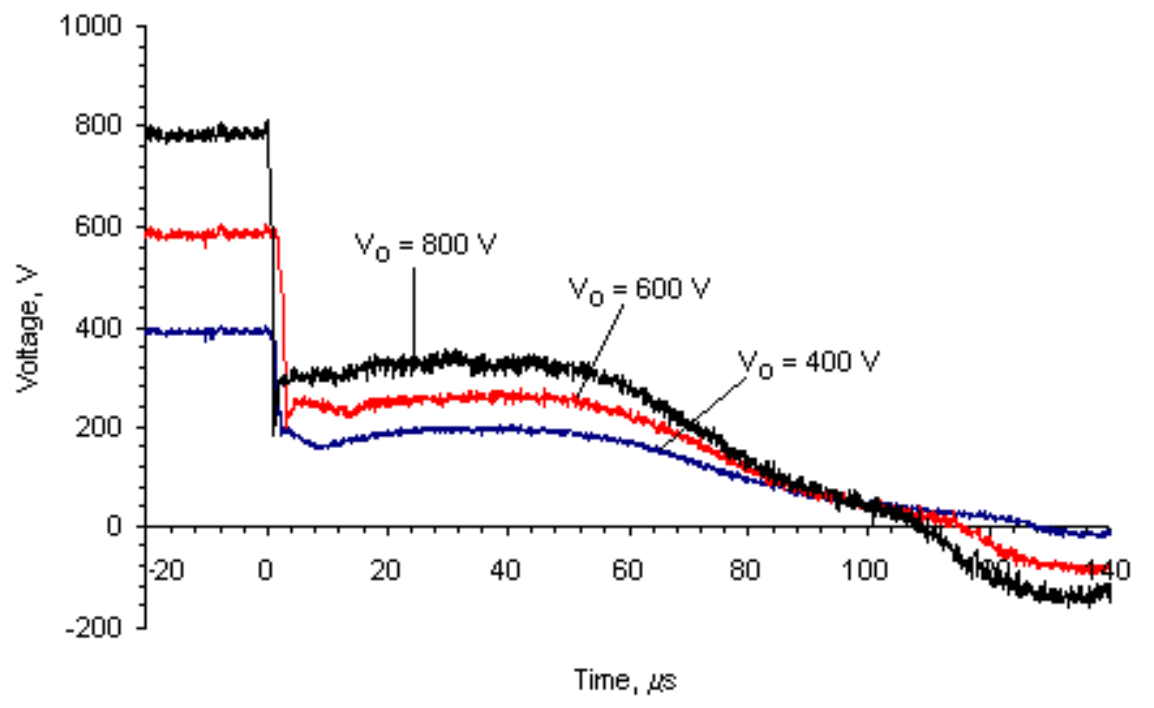

Figure 6. Terminal voltage traces for a PFN charging voltage of 400, 600, and $800 \mathrm{~V}$.

Several things can be noted from these figures. It can be seen that the "flat top" portion of the current pulse is not actually flat; this is attributed to the skin depth effect in the $3.2 \mathrm{~mm}$ inductors, and can be resolved in the future by using section inductors with a larger cross sectional area. Additionally, there is a lack of high frequency oscillation in the voltage trace indicating that the arc is operating below onset and that there are a sufficient number of gallium ions present for adequate current conduction at these discharge current levels $(\alpha \geq 1)$.

\section{Mass Consumption Estimate}

The mass flow rate is calculated using two separate methods. Rearranging Eq. (1), the mass flow rate can be calculated directly from the discharge current (assuming $\alpha=1$ )

$$
\frac{\mathrm{d} m}{\mathrm{~d} t}=\frac{m I}{Z e}
$$

The amount of gallium vaporized and ionized per pulse can also be estimated by considering a power balance at the anode surface $^{14}$

$$
P_{\text {res }}+P_{e l}=P_{\text {vap }}+P_{\text {cond }}+P_{\text {rad }}
$$

Anode heating takes place by resistive heating $P_{\text {res }}$ and electron bombardment $P_{e l}$. The power is dissipated through vaporization $P_{\text {vap }}$, conduction $P_{\text {cond }}$ and radiation $P_{\text {rad }}$. The problem of a source of uniform current density acting over a circular area on the surface of a semi-infinite solid of conduction material has been solved and the resulting power input due to Joule heating has the form ${ }^{15}$

$$
P_{r e s}=\frac{0.32 I^{2} \eta_{G a}}{\pi \mathrm{r}_{\mathrm{i}}}
$$

where $\eta_{G a}$ is the electrical resistivity of gallium. The power flux $P_{e l}$ is given by Eq. (3). The power flux $P_{\text {vap }}$ is the power dissipated through evaporation of the anode surface 


$$
P_{\text {vap }}=h_{\text {tot }} \frac{\mathrm{d} m}{\mathrm{~d} t}
$$

The total enthalpy $h_{\text {tot }}$ is comprised of the enthalpy needed for a phase change (enthalpy of fusion + enthalpy of vaporization) and then raising the gas temperature to the arc temperature as given by ${ }^{16}$

$$
h_{\text {tot }}=h_{f}+h_{v}+c_{p} \Delta T
$$

To calculate the power dissipated by thermal conduction, it is assumed that the anode material is a semi-infinite solid and that the steady state is quickly reached for thermal flow ${ }^{17}$

$$
P_{\text {cond }}=\pi^{3 / 2} \lambda\left(T_{s}-T_{o}\right) r_{i}
$$

where $T_{o}$ is the initial temperature $(298 \mathrm{~K})$ and $\lambda$ is the thermal conductivity. The power dissipated through radiation can be estimated as

$$
P_{\text {rad }}=\sigma_{s b} T_{s}^{4} \pi r_{i}^{2}
$$

where $\sigma_{s b}$ is the Stefan-Boltzmann constant, which has a value of $5.67 \mathrm{~W} / \mathrm{m}^{2}-\mathrm{K}^{4}$. Using equations (5)-(10), one can solve for the mass flow rate

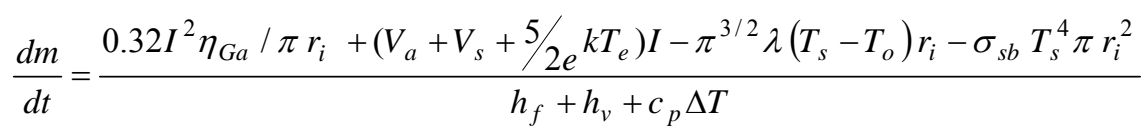

The computed mass flow rates are given as a function of discharge current in Fig. 10. A sheath voltage and electron temperature of $6 \mathrm{~V}$ and $3.5 \mathrm{eV}$, respectively, are used. It can be seen that the mass flow rate calculated from an anode power balance gives a value slightly less than a doubly-ionized $(Z=2)$ plasma. An experimentally based estimate of $Z$ is given below in Section IV B. Based on these estimates, we adopt $Z=2$ pending further measurements including spectral data.

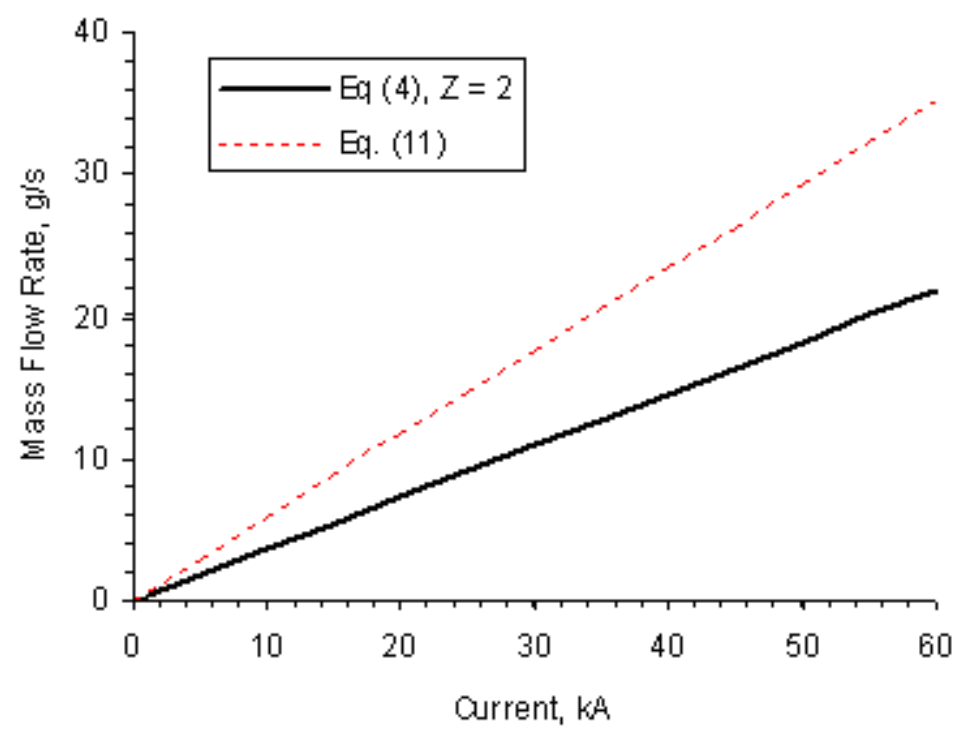

Figure 10. Comparison of calculated mass flow rates. 


\section{Discussion}

\section{A. Efficiency Estimate}

The current and voltage data acquired during testing are summarized in Table 2. Also shown in the table are the arc impedance and the dynamic impedance $Z_{L}$, which is found from

$$
Z_{L}=\frac{1}{4} L^{\prime} u_{e}
$$

The relation for the inductance gradient L' can be found from the EM thrust relation ${ }^{18}$

$$
T=\frac{1}{2} L^{\prime} I^{2}=\frac{\mu_{o} I^{2}}{4 \pi}\left(\ln \frac{r_{o}}{r_{i}}+\frac{1}{2}\right)=b I^{2} \Rightarrow \Rightarrow \frac{\mathrm{d} L}{\mathrm{~d} x}=2 b
$$

where the geometric constant $b$ has a numeric value of $2.02 \times 10^{-7} \mathrm{H} / \mathrm{m}$ for our configuration.

Table 2. Plasma Electrical Characteristics at $\mathrm{t}=45 \mu \mathrm{s}$

\begin{tabular}{cccccc}
\hline $\begin{array}{c}\text { PFN } \\
\text { Charging } \\
\text { Voltage, V }\end{array}$ & $\begin{array}{c}\text { Peak } \\
\text { Current, kA }\end{array}$ & $\begin{array}{c}\text { Terminal } \\
\text { Voltage, V }\end{array}$ & $\begin{array}{c}\text { Arc } \\
\text { Impedance, } \\
\mathrm{m} \Omega\end{array}$ & $\begin{array}{c}\text { Dynamic } \\
\text { Impedance, } \\
\mathrm{m} \Omega(\mathrm{Z}=1)\end{array}$ & $\begin{array}{c}\text { Dynamic } \\
\text { Impedance, } \\
\mathrm{m} \Omega(\mathrm{Z}=2)\end{array}$ \\
\hline 300 & 19.6 & 136 & 6.9 & 0.5 & 1.1 \\
400 & 26.0 & 180 & 6.9 & 0.7 & 1.5 \\
500 & 34.8 & 220 & 6.3 & 1.0 & 2.0 \\
600 & 41.5 & 255 & 6.1 & 1.2 & 2.3 \\
700 & 49.5 & 303 & 6.1 & 1.4 & 2.8 \\
800 & 54.0 & 330 & 6.1 & 1.5 & 3.0 \\
\hline
\end{tabular}

The exhaust velocity is found by dividing the thrust by the mass flow rate

$$
u_{e}=\frac{T}{\dot{m}}
$$

The thrust efficiency is calculated from the ratio of the dynamic impedance to the arc impedance, assuming that thermal heating does not add to the thrust

$$
\eta=\frac{Z_{L}}{Z_{\text {arc }}}=\frac{L^{\prime} T / \dot{m}}{4 Z_{\text {arc }}}
$$

The exhaust velocity as a function of discharge current is plotted in Fig. 7, yielding a specific impulse of $3000 \mathrm{~s}$ at a discharge current of $54 \mathrm{kA}$. The efficiency as a function of the specific impulse is shown in Fig. 8. It can be seen that the efficiency is a linear function of the specific impulse. 


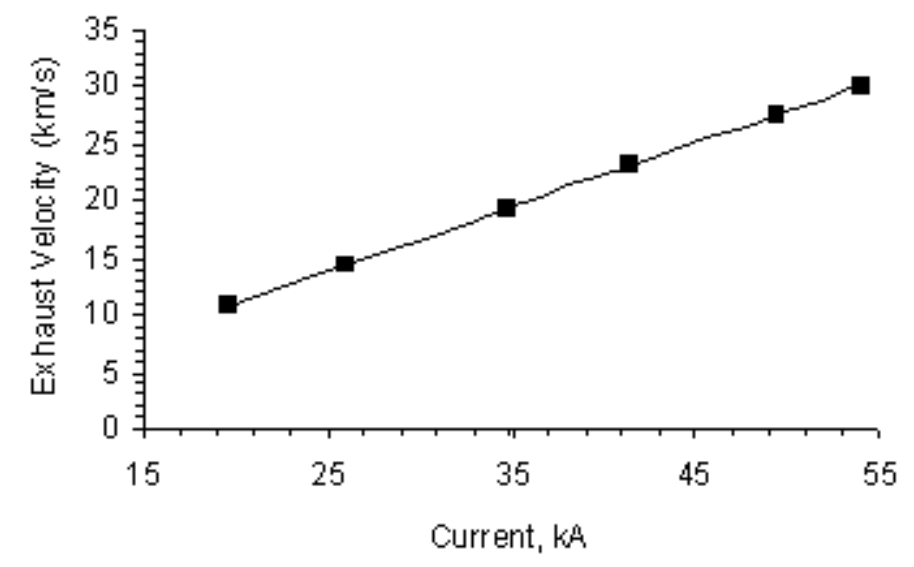

Figure 7. Exhaust velocity as a function of the discharge current for an estimated value of $Z=2$.

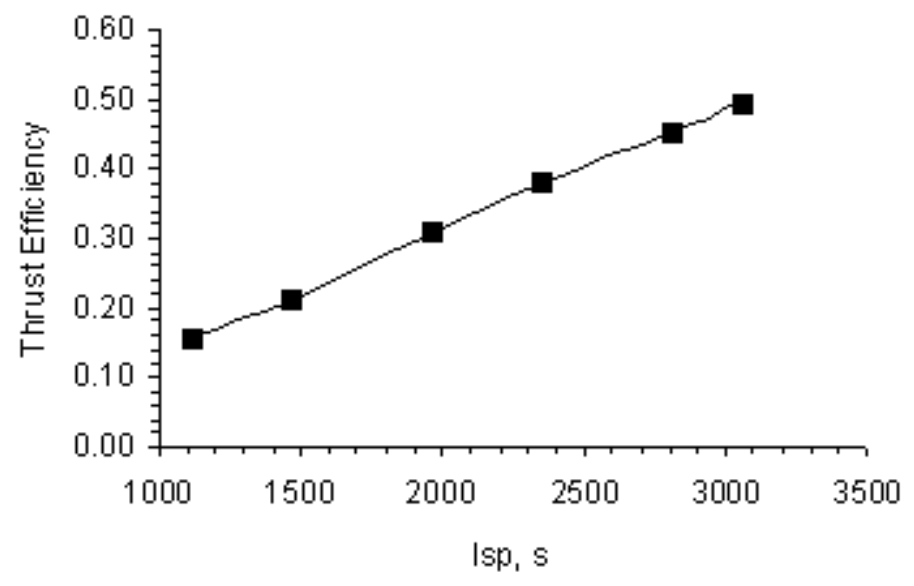

Figure 8. Thrust efficiency as a function of the discharge current for an estimated value of $Z=2$..

In the next subsection, a simple model is used to estimate the electron temperature to support the claim that the plasma is doubly ionized.

\section{B. Electron Temperature Calculation}

Using Gauss's Law and assuming a spherical geometry, the electric field has a $1 / \mathrm{r}^{2}$ dependence

$$
E_{r}=\frac{C_{1}}{r^{2}}
$$

Noting the electric field is the gradient of the electric potential, the integration constant $C_{1}$ can be found

$$
\Delta V=-\int_{r_{i}}^{r_{o}} \frac{C_{1}}{r^{2}} \mathrm{~d} r \Rightarrow \Rightarrow C_{1}=\Delta V\left(\frac{1}{r_{i}}-\frac{1}{r_{o}}\right)^{-1}
$$

The current density is also assumed to have a $1 / \mathrm{r}^{2}$ dependence 


$$
J=\frac{I}{\pi \mathrm{r}^{2}}
$$

Ohm's Law directly relates the current density to the electric field

$$
j=\sigma_{\mathrm{o}}(\mathbf{E}+\mathbf{u} \times \mathbf{B})+\frac{\Omega}{B}(\mathbf{j} \times \mathbf{B})
$$

The estimated hall parameter $\Omega$ is small so the last term is neglected, and assuming $\mathbf{u}$ is radial, equations (16) - (19) can be combined to yield an expression for the electrical conductivity

$$
\sigma_{\mathrm{o}}=\frac{I}{\pi \Delta \mathrm{V}}\left(\frac{1}{r_{i}}-\frac{1}{r_{o}}\right)
$$

The electron temperature is related to the scalar conductivity through the relation

$$
\sigma_{\mathrm{o}}=\frac{e^{2} n_{e}}{m_{e} v_{e i}} \approx 1.3 \times 10^{4} \frac{T_{e}^{3 / 2}}{Z \ln \Lambda} \quad(\mathrm{S} / \mathrm{m})
$$

where $v_{e i}$ is the electron-ion collision frequency, $m_{e}$ is the electron mass, $\ln \Lambda$ is estimated to be $\sim 3$, and the electron temperature is in units of $\mathrm{eV}$. The conductivity and electron temperature are calculated using the experimental data and are shown in Table 3. The potential difference $\Delta V$ and current $I$ used to calculate the conductivity in Eq. (20) are taken to be the terminal voltage and peak current values located in Table 2.

Table 3. Calculated Conductivity and Temperature

\begin{tabular}{ccccc}
\hline $\begin{array}{c}\text { PFN } \\
\text { Charging } \\
\text { Voltage, }\end{array}$ & $\begin{array}{c}\text { Arc } \\
\text { Current, } \\
\mathrm{kA}\end{array}$ & $\begin{array}{c}\text { Arc } \\
\text { Impedance, } \\
\mathrm{m} \Omega\end{array}$ & $\begin{array}{c}\text { Electrical } \\
\text { Conductivity, } \\
\mathrm{S} / \mathrm{m}\end{array}$ & $\begin{array}{c}\text { Electron } \\
\text { Temperature, } \\
\mathrm{eV}(\mathrm{Z}=2)\end{array}$ \\
\hline 300 & 19.6 & 6.9 & 14217 & 3.5 \\
400 & 26.0 & 6.9 & 14249 & 3.5 \\
500 & 34.8 & 6.3 & 15582 & 3.7 \\
600 & 41.5 & 6.1 & 16054 & 3.8 \\
700 & 49.5 & 6.1 & 16116 & 3.8 \\
800 & 54.0 & 6.1 & 16142 & 3.8 \\
\hline
\end{tabular}

This data provides a rough estimate of the degree of ionization. Cassibry ${ }^{19}$ has calculated equilibrium conditions for gallium plasmas and has found $\mathrm{Z}=3.5$ at $5 \mathrm{~Pa}$ and $3 \mathrm{eV}$. The ionization fraction as a function of pressure is shown below in Fig. 9. Calculations at 50 atm yield a $Z=2.0$ for $\mathrm{T}=3.5 \mathrm{eV}$. Because the pressure will decrease significantly away from the anode, $Z$ is expected to vary from 2.0 to 3.5 in the discharge. We therefore have adopted a conservative value of $Z=2$ for our preliminary calculations. 


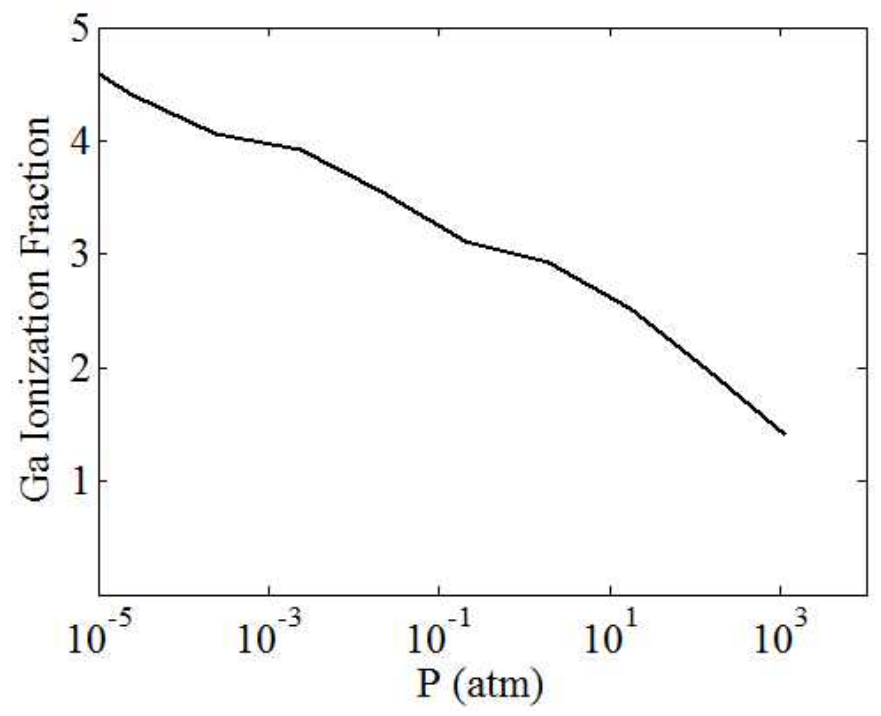

Figure 9. Gallium ionization fraction as a function of pressure for an electron temperature of $3.5 \mathrm{eV}$.

\section{Summary}

The results obtained can be summarized as follows:

- Experiments were conducted at discharge currents in the range of 19-54 kA. At these high currents and short pulse lengths, fast valves are not practical, and a method of mass injection such as evaporation presents itself as a viable alternative.

- Arc impedances in the range of 6-7 $\mathrm{m} \Omega$ were measured from the current and terminal voltage. These low values compare favorably with prior EMTs and are required for high efficiency. The arc impedance slightly decreases with increasing current, suggesting the electron temperature increases with the discharge current. Electrical conductivity calculations yield an electron temperature of $\sim 3.5 \mathrm{eV}$, and the degree of ionization is conservatively estimated to be $Z=2$.

- High-frequency oscillations in the terminal voltage trace ("onset") were absent for discharge currents as high as $54 \mathrm{kA}$, leading to the conclusion that the arc operates below onset for all conditions tested.

- The mass ablated per pulse was not measured experimentally; however the mass flow rate was calculated using two separate methods, both of which roughly agreed. These calculations also suggest that ions carry the bulk of the current.

- The specific impulse and efficiency both linearly scale with the discharge current. Assuming a $Z=2$ plasma results in a calculated Isp of $3000 \mathrm{~s}$ and a thrust efficiency of $\eta=50 \%$.

\section{Acknowledgements}

The authors gratefully acknowledge discussions with J. Cassibry, University of Alabama Huntsville regarding equilibrium ionization of gallium at high temperature and pressure and calculations provided by him.

\section{References}

${ }^{1}$ Markusic, T.E., Thio, Y.C.F., and Cassibry, J.T., "Design of a high-energy, two stage pulse plasma thruster," 38th AIAA/ASME/SAE/ASEE Joint Propulsion Conference, July 7-10, 2002, AIAA Paper 2002-4125.

${ }^{2}$ Polzin, K.A., Markusic, T.E., Burton, R.L., Thomas, R.E., and Carroll, D.L., "Gallium Electromagnetic (GEM) Thruster Concept and Design," 42 ${ }^{\text {nd }}$ AIAA/ASME/SAE/ASEE Joint Propulsion Conference, July 9-12, 2006, AIAA Paper $2006-4652$.

${ }^{3}$ Thomas, R.E., Burton, R.L., Glumac, N.G., and Polzin, K.A., "Preliminary Spectroscopic Measurements for a Gallium Electromagnetic (GEM) Thruster," 43 ${ }^{\text {rd }}$ AIAA/ASME/SAE/ASEE Joint Propulsion Conference, July 8-11, 2007, AIAA Paper 2007-5257. 
${ }^{4}$ Burkhardt, L.C. and Lovberg, R.H., "Current Sheet in a Coaxial Plasma Gun,” Physics of Fluids, Vol. 5, No. 3, 1962, pp. 341-347.

${ }^{5}$ Cheng, D.Y., "Plasma Deflagration and the Properties of a Coaxial Plasma Deflagration Gun," Nuclear Fusion, Vol. 10, 1970, pp. 305-317.

${ }^{6}$ Paccini, G. and Petrucci, G., "Scale-Effects on Solid Propellant Coaxial Magnetoplasmadynamic Thruster Performance," Journal of Propulsion and Power, Vol. 19, No. 3, 2003, pp. 431-437.

${ }^{7}$ Burton, R.L., Clark, K.E., and Jahn, R.G., "Measured Performance of a Multimegawatt MPD Thruster," Journal of Spacecraft and Rockets, Vol. 20, No. 3, 1983, pp. 299-304.

${ }^{8}$ Ziemer, J.K., Choueiri, E.Y., and Birx, D., "Trends in Performance Improvements of a Coaxial Gas-Fed Pulsed Plasma Thruster," $25^{\text {th }}$ International Electric Propulsion Conference, Aug. 24-28, 1997, IEC Paper 97-040.

'Laystrom, J. and Burton, R., "Geometric Optimization of a Coaxial Pulsed Plasma Thruster," $39^{\text {th }}$ AIAA/ASME/SAE/ASEE Joint Propulsion Conference, July 20-23, 2003, AIAA Paper 2003-5025.

${ }^{10}$ Polk, J., Tikhonov, V., Semenikhin, S., and Kim, V., "Cathode Temperature Reduction by Addition of Barium in HighPower Lithium Plasma Thrusters," AIP Conference Proceedings, edited by M.S. El-Genk, Vol. 504, 2000, pp. 1556.

${ }^{11}$ Collier, R.P. and Scott, D.S., "Cathode Geometry and Spoke Mode Operation of MPD Accelerators," AIAA Journal, Vol. 13, No. 7, 1975, pp. 944-945.

${ }^{12}$ Sokolnikoff, I.S. and Redheffer, R.M., Mathematics of Physics and Modern Engineering, McGraw-Hill, New York, 1958, p. 491.

${ }^{13}$ Oberth, R.C. and Jahn, R.G., "Anode Phenomena in High-Current Accelerators," AIAA Journal, Vol. 10, No. 1, 1972, pp. 86-91

${ }^{14}$ Beilis, I.I., "Anode Spot Vacuum Arc Model: Graphite Anode," IEEE Transactions on Components and Packaging Technologies, Vol. 23, No. 2, 2000, pp. 334-340.

${ }^{15}$ Rich, J.A., "Resistance Heating in the Arc Cathode Spot Zone," Journal of Applied Physics, Vol. 32, No. 6, 1961, pp. 1023-1031.

${ }^{16}$ Burton, R.L. and Turchi, P.J., "Pulsed Plasma Thruster," Journal of Propulsion and Power, Vol. 14, No. 5, 1998, pp. 716-735.

${ }^{17}$ Lefort, A., Parizet, M.J., El-Fassi, and S.E., Abbaoui, "Erosion of Graphite Electrodes," J. Phys. D: Appl. Phys., Vol. 26, 1993, pp. 1239-1243.

${ }^{18}$ Jahn, R.G., Physics of Electric Propulsion, McGraw-Hill, New York, 1968, Chapter 6.

${ }^{19}$ Cassibry, J., Markusic, T., and Wu, S., "Effects of Propellant Injection, Material and Electrode Geometry on the Performance of a Two-Stage Pulsed Plasma Accelerator," 40th AIAA/ASME/SAE/ASEE Joint Propulsion Conference, July 11-14, 2004, AIAA Paper 2004-3641. 